\title{
Correlation between iron self-diffusion and thermal stability in doped iron nitride thin films
}

\author{
Akhil Tayal, ${ }^{1}$ Mukul Gupta, ${ }^{1, a)}$ D. Kumar, ${ }^{1}$ V. R. Reddy, ${ }^{1}$ Ajay Gupta,,${ }^{1, b)}$ S. M. Amir, ${ }^{2}$ \\ Panagiotis Korelis, ${ }^{3}$ and Jochen Stahn ${ }^{3}$ \\ ${ }^{1} U G C-D A E$ Consortium for Scientific Research, University Campus, Khandwa Road, Indore 452 001, India \\ ${ }^{2}$ Jülich Centre for Neutron Science, Forschungszentrum Jülich GmbH, Outstation at MLZ Lichtenbergstrasse 1, \\ 85747 Garching, Germany \\ ${ }^{3}$ Laboratory for Neutron Scattering, Paul Scherrer Institute, CH-5232 Villigen PSI, Switzerland
}

(Received 29 March 2014; accepted 15 July 2014; published online 8 December 2014)

\begin{abstract}
Nanocrystalline Fe-X-N thin films (with doping $\mathrm{X}=0,3.1$ at. \% Al, 1.6 at. \% Zr), were deposited using reactive ion beam sputtering. Magnetization study reveals that the deposited films exhibit a perpendicular magnetic anisotropy. Thermal stability of the films was investigated systematically and it was observed that the structural and the magnetic stability gets significantly enhanced with Al doping, whereas $\mathrm{Zr}$ doping has only a marginal effect. Fe self-diffusion, obtained using polarized neutron reflectivity, shows a suppression with both additives. A correlation between the thermal stability and the diffusion process gives a direct evidence that the enhancement in the thermal stability is primarily diffusion controlled. A combined picture of diffusion, structural, and magnetic stability has been drawn to understand the obtained results. (C) 2014 AIP Publishing LLC. [http://dx.doi.org/10.1063/1.4902962]
\end{abstract}

\section{INTRODUCTION}

Thin films exhibiting magnetic anisotropy are important for technological applications, such as in magnetic memory devices, and high frequency read-write heads. ${ }^{1,2}$ Often, in thin film state magnetic anisotropy results due to an interplay between magneto-crystalline, shape, and magneto-elastic anisotropies, ${ }^{3}$ among these the later has the most significant role in nanocrystalline or amorphous (grain size below ferromagnetic exchange length) thin films. ${ }^{4-6}$ In general, the magnetoelastic anisotropy stems from stresses present in thin films. ${ }^{3}$ Stress generation in thin films has been studied widely, and it was found that it plays a significant role in affecting various properties of the material including its structural and magnetic behaviour. ${ }^{7}$ Generally, stresses develop in thin films due to creation of defects and vacancies during deposition. ${ }^{8-10}$ Apart from it, internal stresses can also be developed by interstitial species. Relaxation of these stresses can be caused by various post-deposition treatments such as vacuum annealing, ion beam, or laser irradiation. ${ }^{11}$ Most importantly, the underlying process that leads to such relaxation phenomenon was a redistribution of constituent atomic species. Therefore, knowledge of atomic diffusion is fruitful in such materials to investigate the underlying mechanism of stress relaxation.

Recently, nanocrystalline iron nitrides $(n-\mathrm{Fe}-\mathrm{N})$ have been a subject of intense research for their vital tribological applications, additionally these compounds exhibits excellent soft magnetic properties with a strong perpendicular magnetic anisotropy. ${ }^{12-14}$ Apart from it, iron nitride can be easily fabricated which adds further salutary features in these compounds. $n-\mathrm{Fe}-\mathrm{N}$ is formed at low nitrogen concentration range $<11$

\footnotetext{
a)Electronic addresses: mgupta@csr.res.in and dr.mukul.gupta@gmail.com

${ }^{b}$ Present address: Amity Center for Spintronic Materials, Amity University, Sector 125, NOIDA 201 303, India.
}

at. $\%,{ }^{15}$ within this range, nitrogen atoms preferentially occupy the interstitial sites which lead to expansion of the Fe lattice. Such expansion generates a significant amount of stress in the deposited films. Apart from this, additional stresses are also generated leading to magnetic anisotropy. ${ }^{16,17}$

It was also observed that the thermal stability of $\mathrm{Fe}-\mathrm{N}$ compounds is rather poor due to weak Fe-N bonding. This results in deterioration of interesting magnetic properties. To overcome this issue, doping or addition of a small amount of third element ( $\sim 3-5$ at. \%) such as $\mathrm{X}=\mathrm{Al}$, Ti, and $\mathrm{Zr}$ was prescribed in the literature, leading to an improvement in the thermal stability. The proposed underlying mechanism suggests an enhancement in the local activation energy of $\mathrm{Fe}$ and $\mathrm{N}$ self-diffusion. However, direct diffusion measurements are not yet available on these compounds.

Among various additives $\mathrm{Zr}$, Ta, $\mathrm{Ti}$, and $\mathrm{Al}$ have been most popular. ${ }^{14,15,18-27}$ Although they show some degree of structural stability, only very few attempts have been made to study the magnetic stability which is deterministic for magnetic applications. Moreover, the choice of additives looks rather arbitrary. The key parameters resulting in enhanced thermal stability are (i) heat of formation $(\Delta \mathrm{H})$ for $\mathrm{X}-\mathrm{N}$, (ii) the affinity $(f)$ of $\mathrm{X}$ for $\mathrm{N}$ as compared to Fe. The values of $\Delta \mathrm{H}$ for $\mathrm{ZrN}, \mathrm{TaN}, \mathrm{TiN}$, and $\mathrm{AlN}$ are $-360,-237$, -338 , and -321 (in $\mathrm{kJ} \mathrm{mol}^{-1}$ ) at room temperature, respectively. ${ }^{28-30}$ The value affinity $f$ with respect to Fe have been determined by Evans and Pehkle and their values for $\mathrm{Zr}$, Ta, $\mathrm{Ti}$, and $\mathrm{Al}$ are $-0.63,-0.032,-0.53$, and -0.028 , respectively. ${ }^{31}$ A lower value of $\Delta \mathrm{H}$ and $f$ indicates ease of nitride formation and higher affinity. Clearly, $\mathrm{Zr}$ looks like a perfect choice as an additive in the $\mathrm{Fe}-\mathrm{N}$ system.

A mechanism leading to thermal stability with additives was proposed by Das et al. ${ }^{15}$ It was found that when additives are added in a small amount $(<5$ at. $\%)$, they dissolve substitutionally into the bcc lattice with no substantial effect 
on the structure or magnetic properties of Fe-N. By substitutionally dissolving within bcc Fe lattice, additives with a larger atomic size than $\mathrm{Fe}$ may cause an expansion in the lattice resulting in more space available for $\mathrm{N}$ atoms. This suggests that the atomic size of additives may also play a key role in determining thermal stability. Among mostly used additives while $\mathrm{Zr}$ has the largest atomic radius (206 pm, 24\% larger than Fe), $\mathrm{Al}$ has the smallest (118 pm, $24 \%$ smaller than $\mathrm{Fe}$ ). ${ }^{32}$ On the basis of values of $f$ and atomic size, $\mathrm{Zr}$ and $\mathrm{Al}$ looks like two extremes though their $\Delta \mathrm{H}$ is almost comparable. Therefore, it would be interesting to compare how addition of $\mathrm{Zr}$ and $\mathrm{Al}$ affects thermal stability in $\mathrm{Fe}-\mathrm{N}$. We therefore added about 3 at. \% of $\mathrm{Al}$ in $\mathrm{Fe}-\mathrm{N}$. As shown later with our X-ray diffraction (XRD) results, it causes a lattice expansion of about $0.65 \%$ in the bcc Fe lattice. In order to get about similar lattice expansion with $\mathrm{Zr}$ much smaller amount of $\mathrm{Zr}$ is required as its atomic size is about twice of $\mathrm{Al}^{33}$ Therefore, we added 3.1 at. \% of $\mathrm{Al}$ and 1.6 at. \% of $\mathrm{Zr}$ in $\mathrm{Fe}-\mathrm{N}$ thin films to get nearly similar expansion in Fe lattice. The role of Fe diffusion on the thermal stability of samples was investigated using various characterization techniques. Finally, a correlation between $\mathrm{Fe}$ self-diffusion on enhancing the thermal stability in Fe-X$\mathrm{N}$ thin film is discussed from the obtained results.

\section{EXPERIMENTAL}

$\mathrm{Fe}-\mathrm{X}-\mathrm{N}$ thin films were deposited using ion beam sputtering of pure $\mathrm{Fe}$, and composite $[\mathrm{Fe}+\mathrm{Al}]$ and $[\mathrm{Fe}+\mathrm{Zr}]$ targets. An ion beam of energy $1000 \mathrm{eV}$, current $30 \mathrm{~mA}$ was produced using an RF ion source with a mixture of argon and nitrogen gases flowing at different partial pressures. Total gas flow was kept constant at $4 \mathrm{sccm}$ and nitrogen partial pressure, $\mathrm{R}_{\mathrm{N}_{2}}=\mathrm{P}_{\mathrm{N}_{2}} /\left(\mathrm{P}_{\mathrm{N}_{2}}+\mathrm{P}_{\mathrm{Ar}}\right) \times 100 \%$, was varied at $0 \%, 12.5 \%$, $25 \%$, and $50 \%$. The ion beam was neutralized using electrons generated by an RF neutralizer with argon gas flowing at 5 sccm. A base pressure of $2 \times 10^{-6} \mathrm{~Pa}$ was achieved prior to the deposition, the pressure during deposition was $5 \times 10^{-2} \mathrm{~Pa}$. To remove contamination of other adsorbed gases, the deposition chamber was pressurized and evacuated repeatedly (3-4 times) with $\mathrm{Ar}$ gas. To minimize the surface contamination, the targets were pre-sputtered for about $10 \mathrm{~min}$. To study the self-diffusion of $\mathrm{Fe}$ with neutrons, special isotope multilayer samples of type $\left[\mathrm{Fe}-\mathrm{X}-\mathrm{N}(6 \mathrm{~nm}) /^{57} \mathrm{Fe}-\mathrm{X}-\mathrm{N}(6 \mathrm{~nm})\right]_{\times 10}(\mathrm{X}=0$, $\mathrm{Al}, \mathrm{Zr}$ ) were prepared. Here, identical ${ }^{\text {natural }} \mathrm{Fe}-\mathrm{X}$ and ${ }^{57} \mathrm{Fe}-\mathrm{X}$ composite targets were alternatively sputtered. Overall thickness of all the samples was about $120 \mathrm{~nm}$.

Secondary ion/neutral mass spectroscopy (SIMS/ SNMS) measurements were carried out to determine nitrogen/additive concentration using the Hiden Analytical SIMS workstation. The SIMS measurements were performed using an $\mathrm{O}_{2}^{+}$ion beam of energy $5 \mathrm{keV}$ and current $400 \mathrm{nA}$ while for the SNMS measurements an $\mathrm{Ar}^{+}$ion beam of energy $5 \mathrm{keV}$ and current $500 \mathrm{nA}$ was used. With a base pressure of $5 \times 10^{-8} \mathrm{~Pa}$, the pressure during the SIMS/SNMS measurements was about $8 \times 10^{-6} \mathrm{~Pa}$.

XRD was used to analyze the structure of the deposited samples using a standard X-ray diffractometer (Bruker D8 Advance) equipped with $\mathrm{Cu} \mathrm{k}-\alpha \mathrm{x}$-rays source operating in $\theta-2 \theta$ geometry. The XRD measurements were performed on the as-deposited and the annealed samples. Thermal annealing of the samples was done in a vacuum furnace with a base pressure of about $1 \times 10^{-5} \mathrm{~Pa}$. The samples were annealed for $1 \mathrm{~h}$ at each temperature. In order to avoid any thermal gradient, all samples of a type were annealed simultaneously at a particular temperature.

Magnetic anisotropy measurements in the samples were carried out using Quantum Design Inc. make superconducting quantum interference device-vibrating sample magnetometer (S-VSM), conversion electron Mössbauer spectroscopy (CEMS), and magneto optic Kerr effect (MOKE) setups. The CEMS measurements were carried out using a ${ }^{57} \mathrm{Co}$ source embedded in Rh matrix, the conversion electrons were detected in a proportional counter having a mixture of helium and methane $(5 \%)$ gas. After confirming perpendicular magnetic anisotropy (PMA) in the samples, detailed thermal stability of the PMA was done in a specialized in-situ MOKE system. As MOKE is a surface sensitive technique, in-situ annealing in a pressure of about $2 \times 10^{-8}$ $\mathrm{Pa}$ reduces the probability of formation of a surface oxide layer.

Self-diffusion measurements of iron were carried out using polarized neutron reflectivity (PNR) at AMOR SINQ/PSI, Switzerland. ${ }^{34}$ The measurements were performed at a fixed angle of incidence in the time-of-flight mode. A magnetic field of strength about $0.5 \mathrm{~T}$ was applied to saturate the samples magnetically. The reflectivity of the samples was measured in the as-deposited state and after annealing them at different temperatures. Here also samples of a particular type were annealed together to reduce any temperature variations.

\section{RESULTS AND DISCUSSION}

\section{A. SIMS and SNMS measurements}

SIMS measurements were carried out to obtained nitrogen concentration in the samples. An iron mononitride thin film sample with a known nitrogen concentration of about 50 at. \% was used as a reference, ${ }^{35,36}$ and atomic percentage was obtained, as shown in Fig. 1(a). It was found that $\mathrm{R}_{\mathrm{N}_{2}}=12.5 \%, 25 \%$, and $50 \%$, correlates in at. $\%$ as $2.7 \%$, $5.5 \%$, and $11 \%$. Typical error bars are about 1.5 at. $\%$. As can be seen with the addition of $\mathrm{Al}$ or $\mathrm{Zr}$, within the experimental accuracy, nitrogen concentration remains almost similar. Moreover, $\mathrm{Al}$ and $\mathrm{Zr}$ composition in the samples was obtained using SNMS as shown in Fig. 1(b). The composition of $\mathrm{Al}(3.1$ at. \%) and $\operatorname{Zr}(1.6$ at. \%) was quantified following the process discussed in Refs. 33 and 37. For structural, magnetic, and diffusion measurements samples with 11 at. $\% \mathrm{~N}$ were studied and they are denoted as $\mathrm{Fe}-\mathrm{N}$, $\mathrm{Fe}-\mathrm{Al}-\mathrm{N}$, and $\mathrm{Fe}-\mathrm{Zr}-\mathrm{N}$.

\section{B. Structural stability of Fe-X-N thin films}

It is well-known that when iron is sputtered in the presence of nitrogen, nitrogen atoms tend to occupy interstitial sites within the bcc-Fe lattice, this results in tetragonal distortion (stress) of the bcc structure which induces magnetic 


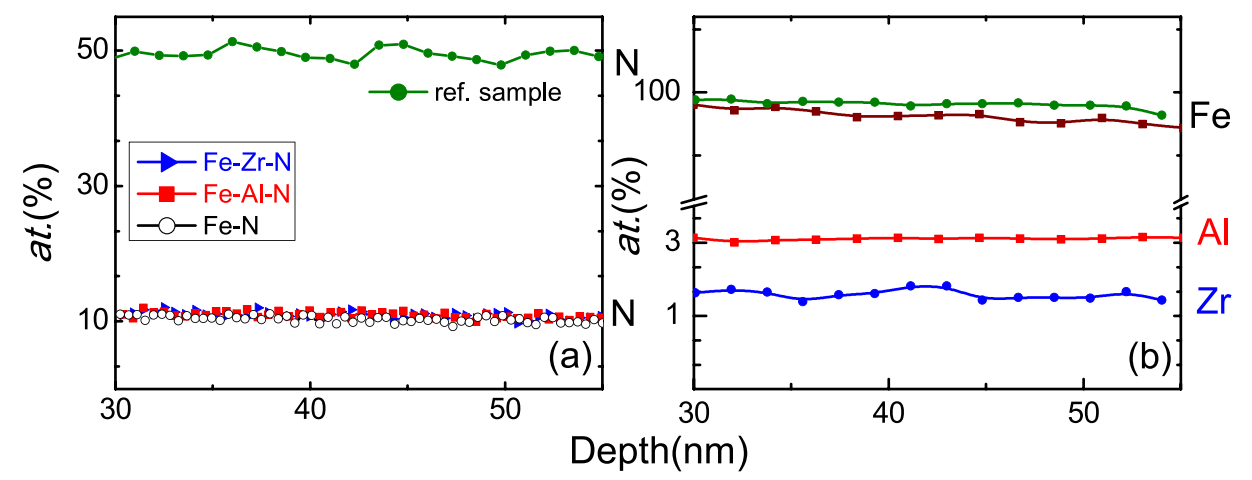

FIG. 1. SIMS depth profile of nitrogen in $\mathrm{Fe}-\mathrm{N}, \mathrm{Fe}-\mathrm{Al}-\mathrm{N}, \mathrm{Fe}-\mathrm{Zr}-\mathrm{N}$, and that of a reference iron mononitride sample(a). SNMS depth profile for $\mathrm{Al}$ and $\mathrm{Zr}$ in $\mathrm{Fe}-\mathrm{Al}-\mathrm{N}$ and $\mathrm{Fe}-\mathrm{Zr}-\mathrm{N}$ thin films(b).

anisotropy in the sample. The maximum amount of nitrogen that can be incorporated at the interstitial sites in bcc-Fe is about 11 at. \%, a value exceeding this results in the formation of various other $\mathrm{Fe}-\mathrm{N}$ compounds. ${ }^{38,39}$

A systematic evolution of $\mathrm{Fe}-\mathrm{N}$ phases can simply be obtained by varying the nitrogen partial pressure starting with zero to a desired value. As studied in great detailed by many co-workers, ${ }^{40-52}$ the evolution of $\mathrm{Fe}-\mathrm{N}$ phases $(\mathrm{Fe}-\mathrm{N}$ phase diagram ${ }^{38}$ ) with increasing nitrogen content can be summarized as: $\alpha-\mathrm{Fe}-\mathrm{N}(\mathrm{N}$ at. $\%=0-11), \quad \alpha^{\prime \prime}-\mathrm{Fe}_{16} \mathrm{~N}_{2}(\mathrm{~N}$ at. $\%=11.4), \gamma^{\prime}-\mathrm{Fe}_{4} \mathrm{~N}(\mathrm{~N}$ at. $\% \sim 20) \varepsilon-\mathrm{Fe}_{3-\mathrm{y}} \mathrm{N}(0 \leq \mathrm{y} \leq 1$, $\mathrm{N}$ at. $\%=25-33), \quad \zeta-\mathrm{Fe}_{2} \mathrm{~N} \quad(\mathrm{~N}$ at. $\% \sim 33), \quad \gamma^{\prime \prime \prime}-\mathrm{FeN} \quad(\mathrm{N}$ at. $\% \sim 50)$. In the present work, we deposited a series of Fe$\mathrm{N}$ thin films by varying the nitrogen partial pressure. XRD patterns of the resulting films are shown in Fig. 2. We did XRD scans in $2 \theta$ range from $30^{\circ}$ to $90^{\circ}$ and observed a peak corresponding to (110) plane of bcc $\alpha$-Fe. Other peaks corresponding to this phase are too small to be measured experimentally and therefore XRD patterns are shown for $2 \theta$ range from $35^{\circ}$ to $55^{\circ}$ for better comparison. As nitrogen concentration in the sample increases this peak becomes broader and shift continuously towards lower angle. This is a typical behavior observed in this system, which clearly indicates the incorporation of nitrogen into the interstitial sites of bcc-Fe. We also increased the $\mathrm{N}$ at. $\%$ to about $20 \%$, and in this case mixed $\alpha$-Fe and $\varepsilon-\mathrm{Fe}_{3-\mathrm{y}} \mathrm{N}(0 \leq \mathrm{y} \leq 1)$ phases are formed as expected (not shown in Fig. 2). Additionally, it was observed that with an increase in $\mathrm{N}$ at. \%, the average grain size (calculated using Scherrer formula ${ }^{53}$ ) decreases continuously. Inter-atomic spacing in a disordered nanocrystalline system was generally calculated using following expression, $a=1.23 \lambda / 2 \sin \theta$, where $\lambda$ is $\mathrm{x}$-ray wavelength, $\theta$ is the angle at the center of the peak, and 1.23 is a geometric factor which rationalizes the nearest neighbor distance with the spacing between "pseudo-close packed planes," 54 it was observed that it increases almost linearly in Fe-N samples. With the addition of $\mathrm{Al}$ or $\mathrm{Zr}$, this behavior remains almost identical. However for 11 at. \% $\mathrm{N}$ samples (which are studied in detail), the value of $a$ is significantly smaller for Al doped sample as compared to undoped or $\mathrm{Zr}$ doped samples. An increase in the value of $a$ with increasing $\mathrm{N}$ at. \% is also a measure of stress generated by interstitial incorporation of nitrogen in the system. Since for 11 at. $\% \mathrm{~N}, a$ is maximized and therefore these samples are expected to show maximum magnetic anisotropy, we therefore have chosen these samples to investigate their structural and magnetic stability.

Figs. 3(a)-3(c) show XRD patterns of pristine and annealed $\mathrm{Fe}-\mathrm{N}, \mathrm{Fe}-\mathrm{Al}-\mathrm{N}$, and $\mathrm{Fe}-\mathrm{Zr}-\mathrm{N}$ samples. It can be seen here that annealing of samples up to a temperature of $423 \mathrm{~K}$ has no significant effect on the XRD patterns except a

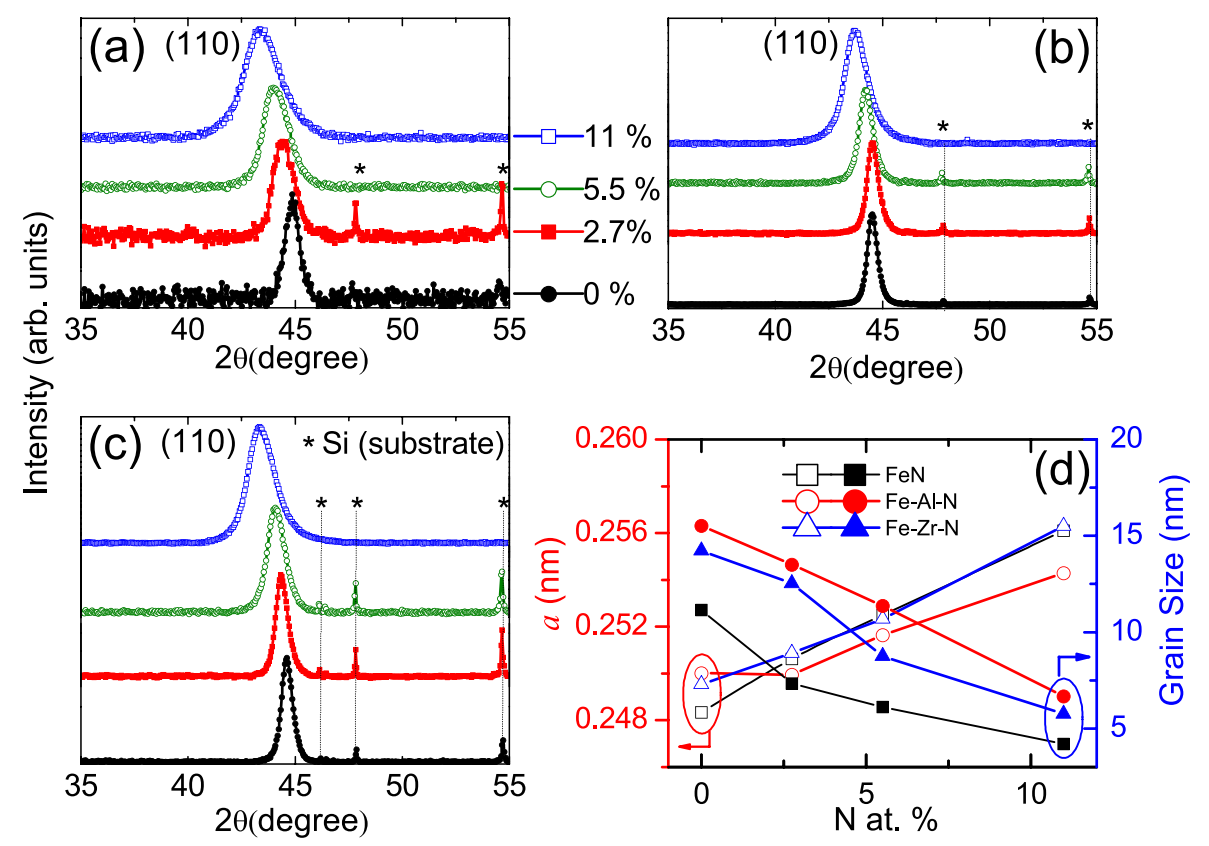

FIG. 2. XRD patterns of Fe-N (a), $\mathrm{Fe}-\mathrm{Al}-\mathrm{N}(\mathrm{b})$, and $\mathrm{Fe}-\mathrm{Zr}-\mathrm{N}$ (c) samples deposited at $0 \%, 12.5 \%, 25 \%$, and $50 \%$ nitrogen partial pressure. Changes observed in the inter atomic spacing (a) and the grain size with increasing nitrogen content are shown in (d), here solid and open symbols show the variation of grain size and inter-atomic spacing, respectively, with increasing nitrogen concentration(obtained from SIMS measurements). 


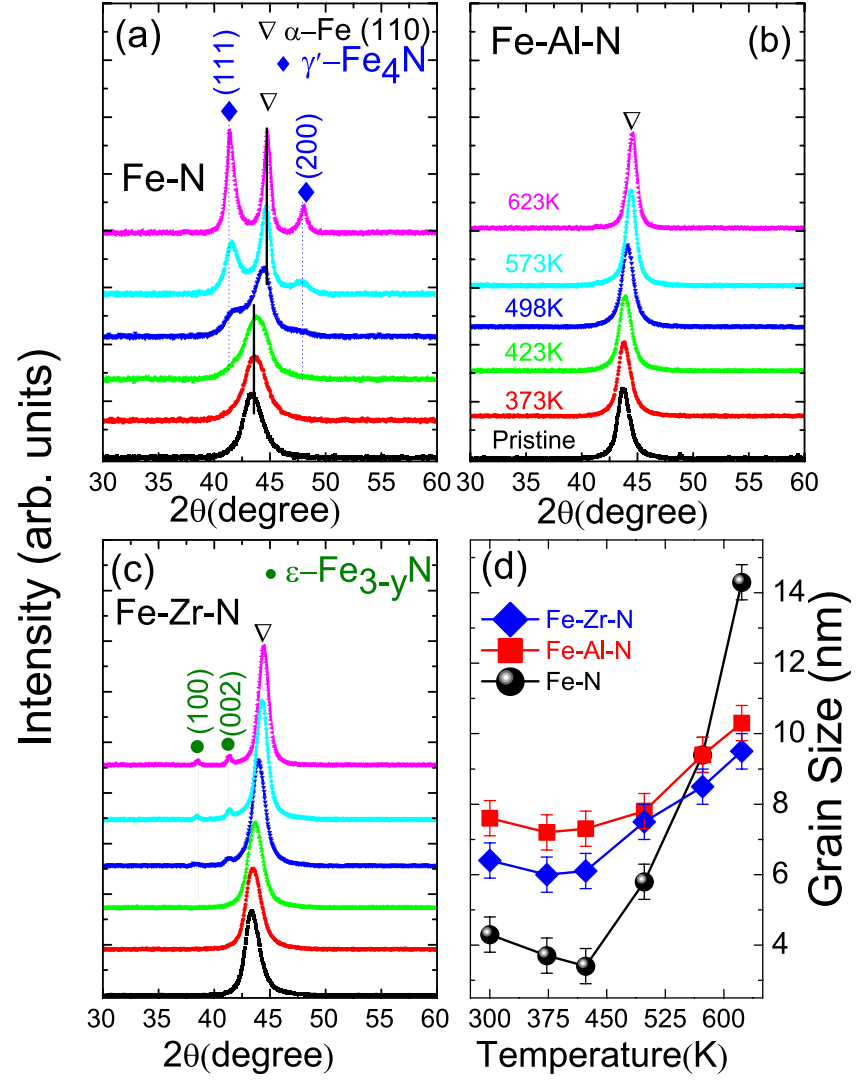

FIG. 3. XRD patterns of Fe-N (a), Fe-Al-N (b), and Fe-Zr-N (c) samples annealed at various temperatures, for better comparison scales are vertically translated. (d) shows variation of grain size with temperature.

continuous shift in the peak position towards higher angle indicating stresses relaxation. ${ }^{16}$ The sample prepared without additives starts showing peaks corresponding to $\gamma^{\prime}-\mathrm{Fe}_{4} \mathrm{~N}$ phase above $423 \mathrm{~K}$ and this phase grows further as annealing temperature is increased. On the other hand addition of $\mathrm{Zr}$ indeed causes some stability in the structure but faint peaks corresponding to $\varepsilon-\mathrm{Fe}_{3-\mathrm{y}} \mathrm{N}$ phase become visible above $498 \mathrm{~K}$. Whereas in the Al added sample no such change in the structure was observed even after annealing at $623 \mathrm{~K}$.

From the XRD patterns grain size at various annealing temperatures was calculated using the most intense peak. Fig. 3(d) shows the obtained grain size for Fe-N, Fe-Al-N, and $\mathrm{Fe}-\mathrm{Zr}-\mathrm{N}$ samples at various annealing temperatures. It can be seen that, in the Fe-N sample there is a sudden growth in the grain size above $498 \mathrm{~K}$ and it continues to grow further with annealing. However in $\mathrm{Al}$ or $\mathrm{Zr}$ added samples no such sudden grain growth can be seen. The modified phase transformation for $\mathrm{Zr}$ added sample correlates well with the previous studies on Fe-X-N thin films. ${ }^{30,33,55}$ On the basis of the above observations, it can deduce that while $\mathrm{Al}$ addition leads to the great enhancement in the thermal stability of iron nitride films, $\mathrm{Zr}$ addition seems to be not so effective. To further investigate the role of $\mathrm{Al}$ addition on stability of PMA, we did in-situ MOKE measurements on the $\mathrm{Fe}-\mathrm{N}$ and $\mathrm{Fe}-\mathrm{Al}-\mathrm{N}$ samples which are presented and discussed in Sec. III D.

\section{Perpendicular magnetic anisotropy in Fe-X-N thin films}

Nanocrystalline Fe- $\mathrm{N}$ thin films are known to exhibit $\mathrm{PMA}^{16,20}$ when few at. $\%$ of nitrogen is added to $\mathrm{Fe}$. However, since the thermal stability of Fe-N films is poor, the addition of a third element is required as discussed in Sec. I. To study the effect of $\mathrm{Al}$ or $\mathrm{Zr}$ addition on the PMA, we performed S-VSM, MOKE and CEMS measurements. Fig. 4(a) shows M-H loops obtained using S-VSM, and Fig. 4(b) shows Kerr's hysteresis loops obtained using MOKE for the as-deposited Fe-X-N thin films. A typical "transcritical" shape of the loops suggests that all the films exhibit PMA. ${ }^{16,20,56}$ From the S-VSM data, saturation magnetization $\left(M_{\mathrm{S}}\right)$, coercivity $\left(H_{\mathrm{C}}\right)$, and a ratio of remanent magnetization over saturation magnetization $\left(1-M_{\mathrm{R}} / M_{\mathrm{S}}\right)$ which is a measure of PMA in the system were obtained and are tabulated in Table I. It can be seen from the table that $M_{\mathrm{S}}$ for Fe-N films get reduced with the addition of non-magnetic additives like $\mathrm{Al}$ or $\mathrm{Zr}$, besides the magnitude of $H_{\mathrm{C}}$ is somewhat less for $\mathrm{Al}$ added samples. Along with this, PMA in the film also get somewhat reduced with $\mathrm{Al}$ addition. Similar information is obtained from the MOKE measurements. Since PMA in such films primarily originates due to magneto elastic anisotropy ${ }^{57,58}$ which in turn depends on stresses caused during the deposition itself, additionally, internal stress gets generated by interstitial incorporation of nitrogen. With the addition of $\mathrm{Al}$ it seems that stresses in the deposited film get affected.

Mössbauer spectroscopy is a versatile technique to probe local structure around the resonant nuclei, in addition, the intensity of second and third Mössbauer line can be used to probe magnetic texture in samples. To further confirm the
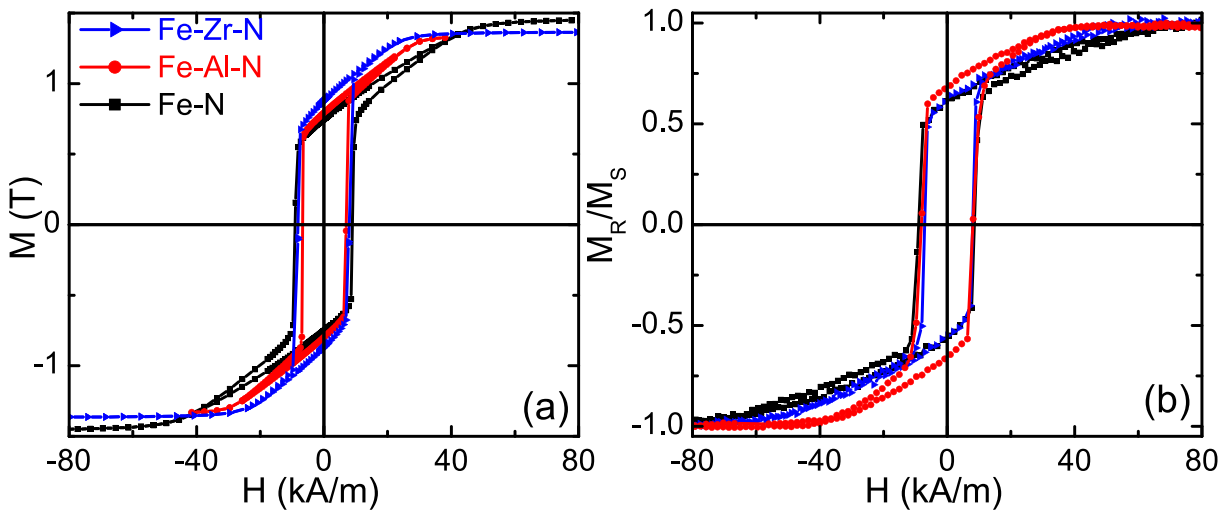

FIG. 4. M-H loops of Fe-N, Fe-Al-N, and $\mathrm{Fe}-\mathrm{Zr}-\mathrm{N}$ samples obtained using S-VSM technique(a), (b)shows Kerr's hysteresis loops of the samples obtained from MOKE measurements. 
TABLE I. Following table shows the value of saturation magnetization $\left(M_{\mathrm{S}}\right)$, coercivity $\left(H_{\mathrm{C}}\right)$, and $M_{\mathrm{R}} / M_{\mathrm{S}}$ as obtained from S-VSM measurements.

\begin{tabular}{lccc}
\hline \hline Sample name & $M_{\mathrm{S}}(\mathrm{T})$ & $H_{\mathrm{C}}\left(\mathrm{kA} \mathrm{m}^{-1}\right)$ & $M_{\mathrm{R}} / M_{\mathrm{S}}$ \\
\hline $\mathrm{Fe}-\mathrm{N}$ & 1.45 & 8.9 & 0.49 \\
$\mathrm{Fe}-\mathrm{Al}-\mathrm{N}$ & 1.32 & 7.0 & 0.40 \\
$\mathrm{Fe}-\mathrm{Zr}-\mathrm{N}$ & 1.36 & 8.0 & 0.48 \\
\hline \hline
\end{tabular}

observed PMA from our S-VSM and MOKE measurements, we have performed CEMS measurements on the asdeposited samples. Fig. 5 shows the CEMS spectra of Fe-N, $\mathrm{Fe}-\mathrm{Al}-\mathrm{N}$, and $\mathrm{Fe}-\mathrm{Zr}-\mathrm{N}$ samples(left) and their corresponding hyperfine field distribution(right) obtained after fitting the CEMS pattern using a computer based software (NORMOS) ${ }^{59}$ It can be clearly seen that all the samples show a broad hyperfine field distribution which may be arise due to random ordering of nitrogen surrounding iron atoms. ${ }^{16,17}$ Additionally, to obtained information on the spin texture the area ratio of second and third line can be used, which gives an angle $(\phi)$ between the average direction of spins with the incident $\gamma$ ray direction. ${ }^{60}$ For the in-plane orientation of spins, $\phi=90^{\circ}$ and for the complete out-of-plane spins orientation $\phi=0^{\circ}$. In our case we find that the values of $\phi=46^{\circ}$ (for $\mathrm{Fe}-\mathrm{N}$ ), $50^{\circ}$ (for $\mathrm{Fe}-\mathrm{Al}-\mathrm{N}$ ), and $46^{\circ}$ (for $\mathrm{Fe}-\mathrm{Zr}-\mathrm{N})$. The observed results correlate well with the S-VSM and MOKE measurements, which suggests that the PMA is slightly reduced with $\mathrm{Al}$ addition.

\section{In-situ MOKE investigation for magnetic stability}

From our S-VSM, MOKE, and CEMS measurements, it is clear that as-deposited samples exhibit PMA. Additionally, the XRD measurements reveal that the thermal stability of iron nitride films gets significantly enhanced with $\mathrm{Al}$ addition. Although, the structural stability of $\mathrm{Fe}-\mathrm{N}$ thin films with additives has been studied in detail, it would be interesting to see the effect of additives on the stability of
PMA. As such it is possible to do S-VSM or CEMS measurements on ex-situ annealed samples, in this study we have performed in-situ MOKE measurements by heating the samples, maintaining a pressure of the order of $2 \times 10^{-8} \mathrm{~Pa}$, which reduces the probability of formation of an oxide layer at the surface. Figs. 6(a) and 6(b) show MOKE patterns of $\mathrm{FeN}$ and $\mathrm{Fe}-\mathrm{Al}-\mathrm{N}$ samples taken at various temperatures. It can be seen that in the $\mathrm{Al}$ added sample there is almost no effect on Kerr hysteresis loops with increasing temperature, whereas in Fe-N sample loops have become square when annealed at or above $453 \mathrm{~K}$. The PMA $\left(1-\mathrm{M}_{\mathrm{R}} / \mathrm{M}_{\mathrm{S}}\right)$ obtained from the measured Kerr's loops are plotted in Fig. 6(c), error bar in the figure represents statistical errors in the measurement. Here, it can be seen that with $\mathrm{Al}$ addition PMA in the film gets significantly stabilized, whereas in $\mathrm{Fe}-\mathrm{N}$ samples there is a sudden decrease in PMA after $453 \mathrm{~K}$ which correlates well with the XRD results where sudden grain growth was observed above this temperature.

\section{E. Diffusion measurements using NR}

From our structural and magnetic measurements, we find that the $\mathrm{Al}$ addition in $\mathrm{Fe}-\mathrm{N}$ results in a remarkable improvement in the structural and magnetic properties. It has been believed that enhancement in thermal stability with additives is due to suppression of atomic diffusion. ${ }^{14}$ However, actual self-diffusion measurements with additives have not yet been performed. It is well-known that neutron reflectivity is a very precise technique to measure self-diffusion using isotopic multilayer down to $10^{-25} \mathrm{~m}^{2} / \mathrm{s} .^{36,41,61-63}$ We therefore have measured iron self-diffusion using neutron reflectivity. Since the neutron scattering length of ${ }^{\text {natural }} \mathrm{Fe}(9.45 \mathrm{fm})$ and ${ }^{57} \mathrm{Fe}$ $(2.3 \mathrm{fm})$ are different, a Bragg's peak is expected to appear in the neutron reflectivity pattern corresponding to bilayer thickness. Moreover, since our samples are magnetic, we have performed PNR measurements in an applied magnetic field $0.5 \mathrm{~T}$, sufficient to saturate magnetically. In this way

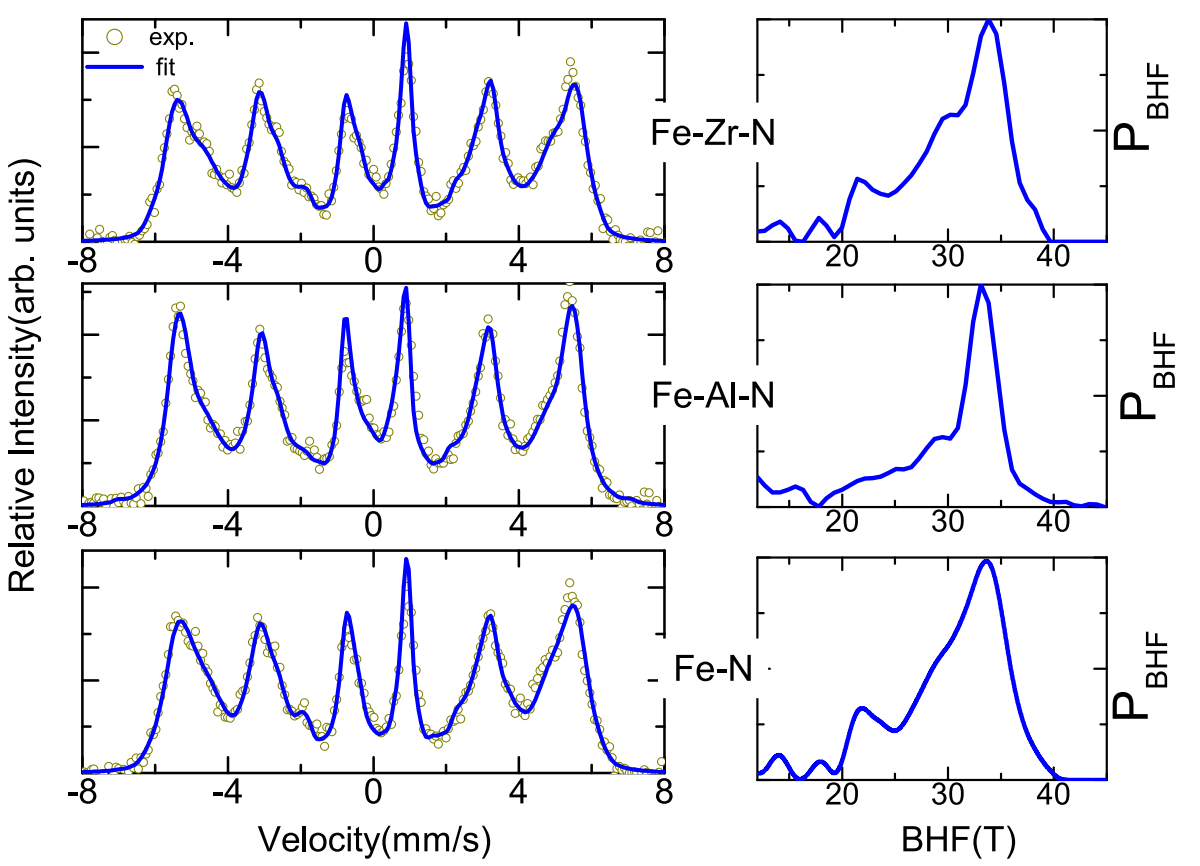

FIG. 5. CEMS patterns of Fe-N (a), $\mathrm{Fe}-\mathrm{Al}-\mathrm{N}$ (b), and $\mathrm{Fe}-\mathrm{Zr}-\mathrm{N}$ (c) thin films. Right of the figure shows the hyperfine field distribution obtained after fitting the CEMS spectra. 

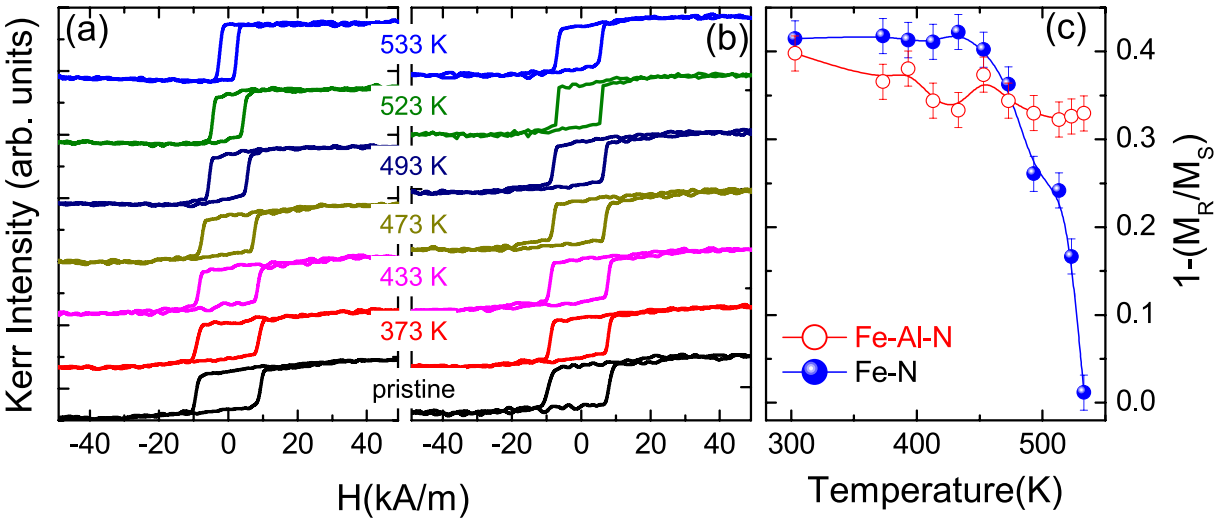

FIG. 6. Representative Kerr's hysteresis loops of $\mathrm{Fe}-\mathrm{N}$ (a) and $\mathrm{Fe}-\mathrm{Al}-\mathrm{N}$ (b) thin films taken at various annealing temperatures. (c) shows variation of PMA in the films with annealing. information about both the self-diffusion process and the magnetic structure samples can be obtained simultaneously. ${ }^{64}$ Fig. 7 shows the spin up reflectivity of as-deposited samples. From the splitting of spin-up and spin-down reflectivity average magnetic moment $\left(\mu_{B}\right)$ per Fe atom can be calculated, ${ }^{65}$ it was found that for $\mathrm{Fe}-\mathrm{N}, \mathrm{Fe}-\mathrm{Al}-\mathrm{N}$, and $\mathrm{Fe}-\mathrm{Zr}-\mathrm{N}$ thin films value of magnetic moment are $1.8 \mu_{B}, 1.65 \mu_{B}$, and $1.7 \mu_{B}$, respectively. These values are in close agreement with the value of saturation magnetization obtained from S-VSM measurements. Inset of Fig. 7 shows spin-up and spin-down PNR patterns of the annealed Fe-N sample, here to comply with measurement time spin-down reflectivity was taken around critical angle region only. As can be seen that with annealing temperatures there is no significant change in magnetic moment although large changes were observed in XRD and MOKE measurements suggest that annealing has no major effect on the total average magnetic moment of the samples.

Figs. 8(a)-8(c) show PNR patterns (spin-up) of FeN, $\mathrm{Fe}-\mathrm{Al}-\mathrm{N}$, and $\mathrm{Fe}-\mathrm{Zr}-\mathrm{N}$ thin films annealed at various annealing temperatures. To calculate $\mathrm{Fe}$ diffusivity the reflectivity pattern is multiplied by $\mathrm{q}_{\mathrm{z}}^{4}$ to remove decay due to Fresnel reflectivity. Due to this, critical edge of total reflection takes the shape of a peak appearing at $\mathrm{q}_{\mathrm{z}}=0.022$

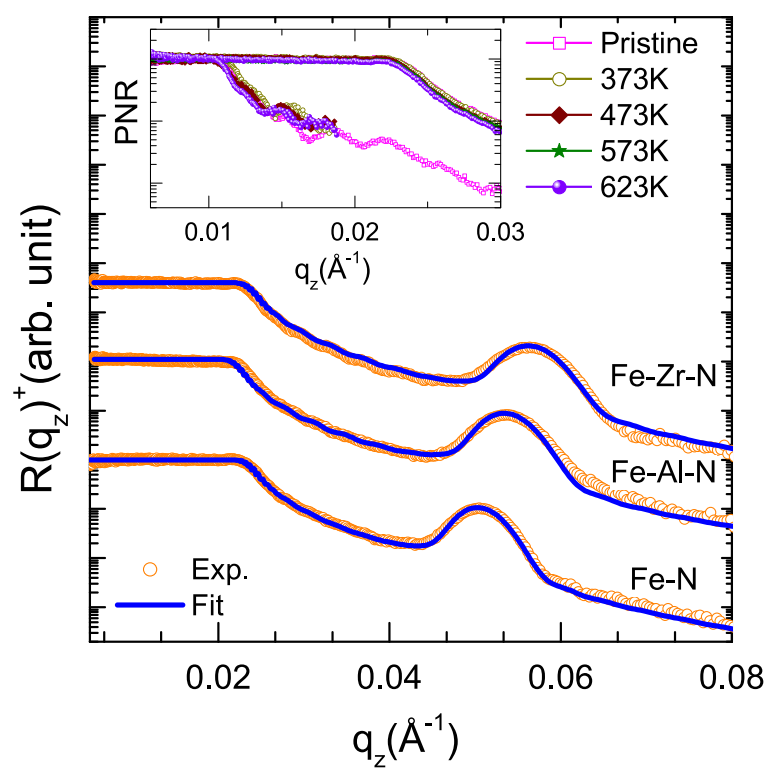

FIG. 7. PNR (spin-up) patterns of as-deposited samples of Fe-N, Fe-Al-N, and $\mathrm{Fe}-\mathrm{Zr}-\mathrm{N}$ thin films. Inset of the figure shows the PNR patterns of $\mathrm{Fe}-\mathrm{N}$ sample annealed at various temperatures.
$\AA^{-1}$. It can be seen that as diffusion takes place, the intensity at Bragg peak decays, which can be used to calculate the diffusion coefficient of Fe using the following expression: ${ }^{66-68}$

$$
\ln [I(t) / I(0)]=-8 \pi^{2} D_{R} t / d^{2}
$$

where $\left(D_{R}\right)$ is the diffusion coefficient, $I(0)$ is the intensity of the first order Bragg peak at time $t=0$ (before annealing), and $d$ is the bilayer thickness. Using Eq. (1) diffusivity of Fe with annealing was calculated and plotted in Fig. 8(d). According to the observed behaviour of Fe diffusion in $\mathrm{Fe}-\mathrm{N}$ thin film, we can divide the range of annealing temperatures into three distinct regions. In region I $(373 \mathrm{~K}-423 \mathrm{~K})$, we find that $\mathrm{Fe}$ diffusion is almost negligible. In region II $(473 \mathrm{~K}-523 \mathrm{~K})$, there is a sudden jump in Fe diffusion and in region III (above $523 \mathrm{~K}$ ), diffusivity increases further though not as steep as in the region II but faster than the region I.

A combined picture of diffusion, structural, and magnetic thermal stability can be seen in Figs. 9(a) and 9(b) for $\mathrm{Fe}-\mathrm{N}$ and Fe-Al-N samples, respectively. Since in the region $\mathrm{I}, \mathrm{Fe}$ diffusion is negligible, grain size, and PMA does not change as well. In the region II, a sudden jump in Fe diffusivity correlates to a sudden increase in the grain size and loss in the PMA. Therefore, apparently it looks that Fe diffusion is the key to control the structural and magnetic stability. By adding $\mathrm{Al}$ or $\mathrm{Zr}$, we find that the sudden increase in diffusion can be avoided and therefore thermally stable region can be extended as shown in Fig. 9(b). Suppression of atomic diffusion of $\mathrm{Fe}$ in presence of $\mathrm{Al}$ or $\mathrm{Zr}$ can be explained in terms of their low heat of formation $(-321$ and $-360 \mathrm{~kJ} \mathrm{~mol}^{-1}$ for AlN and $\mathrm{ZrN}$, respectively, as compared to $-10 \mathrm{~kJ} \mathrm{~mol}^{-1}$ for magnetic $\mathrm{Fe}-\mathrm{N}$ ) and high affinity of $\mathrm{Al}$ and $\mathrm{Zr}$ for $\mathrm{N}$ as compared to Fe. Generally when such additive is added in iron nitride films it may either get dissolved substitutionally within Fe lattice or get accommodated into the grain boundary regions. With low $\Delta \mathrm{H}$ and high affinity of $\mathrm{X}$ for $\mathrm{N}, \mathrm{N}$ may preferentially interact with $\mathrm{X}$ resulting in formation of $\mathrm{X}-\mathrm{N}$ compound. These $\mathrm{X}-\mathrm{N}$ compounds may act as a diffusion barrier for Fe, impeding its diffusion. ${ }^{69}$ The formation of $\mathrm{X}-\mathrm{N}$ compounds in $\mathrm{Fe}-\mathrm{X}-\mathrm{N}$ thin films has been observed in several reports. ${ }^{70-72}$ Our results therefore confirm that the additives have a significant effect on suppressing atomic diffusion of $\mathrm{Fe}$ which leads to improve the thermal stability of iron nitride films. Nevertheless, the discrepancy between the phase transformation behaviour of iron nitride films for $\mathrm{Al}$ or $\mathrm{Zr}$ added samples cannot be 

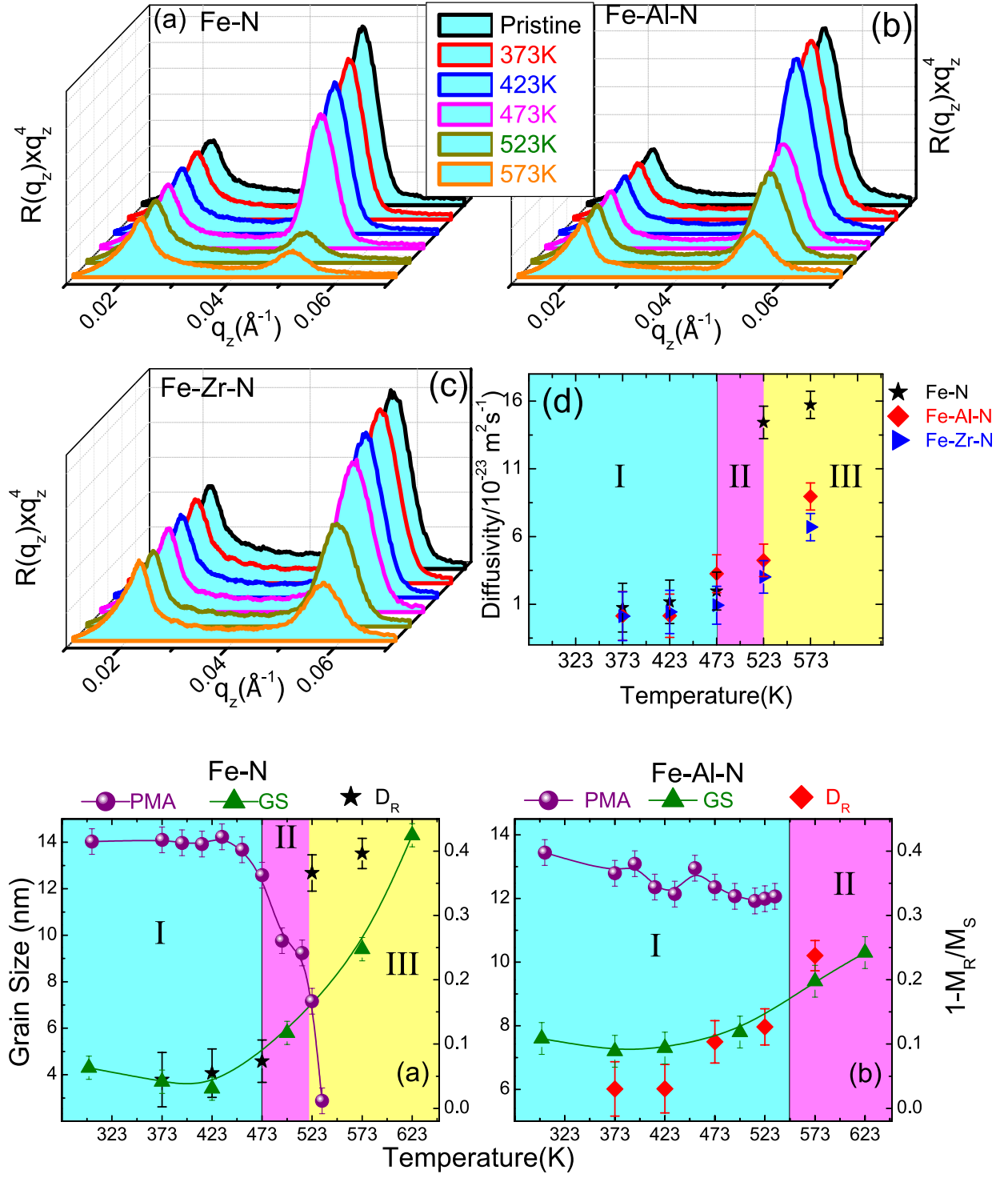

FIG. 8. PNR (spin-up) patterns of Fe$\mathrm{N}$ (a), Fe-Al-N (b), and $\mathrm{Fe}-\mathrm{Zr}-\mathrm{N}$ (c) thin films annealed at various temperatures. Here, spin up reflectivity is multiplied by $\mathrm{q}_{z}^{4}$ to get rid of decay in Fresnel reflectivity. (d) shows the diffusivity calculated using Eq. (1). understood by Fe diffusion behaviour alone, and it seems that the knowledge of $\mathrm{N}$ self-diffusion in the presence of $\mathrm{X}$ is indispensable to understand the complete mechanism of thermal stability in these compounds.

\section{CONCLUSION}

In conclusion, $\mathrm{Fe}-\mathrm{X}-\mathrm{N}$ thin films exhibiting PMA were systematically studied using various characterizing techniques. The role of $\mathrm{X}$ on thermal stability of $\mathrm{Fe}-\mathrm{X}-\mathrm{N}$ thin films was investigated. XRD and in-situ MOKE measurements reveal that structural and magnetic properties of the films get remarkably improved with $\mathrm{Al}$ addition, however $\mathrm{Zr}$ addition has only a marginal effect on the thermal stability of Fe-X-N thin films. Fe self-diffusion measurements were carried out using PNR at various annealing temperatures. It was observed that $\mathrm{Fe}$ diffusion gets remarkably suppressed with additives. On correlating Fe self-diffusivity with the variation of grain size and PMA it was found that Fe selfdiffusion has a significant effect on the thermal stability of $\mathrm{Fe}-\mathrm{X}-\mathrm{N}$ thin films. For pure Fe-N films structural and magnetic instability was driven by Fe diffusion, whereas for $\mathrm{Al}$ added samples due to the suppression of atomic diffusion of Fe thermal stability of the films gets significantly improved. It seems that grain boundary precipitate in the form of $\mathrm{X}-\mathrm{N}$ have a significant effect on the observed behaviour.

\section{ACKNOWLEDGMENTS}

A part of this work was performed at AMOR, Swiss Spallation Neutron Source, Paul Scherrer Institute, Villigen, Switzerland. We acknowledge DST for providing financial support to carry out PNR experiments under its scheme "Utilization of international synchrotron radiation and neutron scattering facilities," Dr. Graham Cooke for the his help in the analysis of SIMS/SNMS data, Dr. R. J. Chaudhary for S-VSM measurements, and Mr. Layanta Behera for XRD measurements. One of the authors (A.T.) thanks to CSIR India for research fellowship.

${ }^{1}$ D. Weller, A. Moser, L. Folks, M. E. Best, W. Lee, M. Toney, M. Schwickert, J. U. Thiele, and M. F. Doerner, IEEE Trans. Magn. 36, 10-15 (2000).

${ }^{2}$ G. van der Laan, J. Phys.: Condens. Matter 10, 3239 (1998).

${ }^{3}$ M. T. Johnson, P. J. H. Bloemen, F. J. A. den Broeder, and J. J. de Vries, Rep. Prog. Phys. 59, 1409 (1996). 
${ }^{4}$ G. Herzer, IEEE Trans. Magn. 25, 3327 (1989).

${ }^{5}$ N. Sulitanu, J. Magn. Magn. Mater. 231, 85-93 (2001).

${ }^{6}$ L. Serrona, A. Sugimura, N. Adachi, T. Okuda, H. Ohsato, I. Sakamoto, A. Nakanishi, M. Motokawa, D. Ping, and K. Hono, Appl. Phys. Lett. 82, 1751-1753 (2003).

${ }^{7}$ J. A. Thornton and D. Hoffman, Thin Solid Films 171, 5-31 (1989).

${ }^{8}$ J. A. Floro, P. G. Kotula, S. C. Seel, and D. J. Srolovitz, Phys. Rev. Lett. 91, 096101 (2003).

${ }^{9}$ G. Janssen, Thin Solid Films 515, 6654-6664 (2007).

${ }^{10}$ H. Windischmann, Crit. Rev. Solid State Mater. Sci. 17, 547-596 (1992).

${ }^{11}$ C. Davis, Thin Solid Films 226, 30 (1993).

${ }^{12}$ C. Navío, J. Alvarez, M. J. Capitan, F. Yndurain, and R. Miranda, Phys. Rev. B 78, 155417 (2008).

${ }^{13}$ C. Navío, J. Alvarez, M. J. Capitan, J. Camarero, and R. Miranda, Appl. Phys. Lett. 94, 263112 (2009).

${ }^{14}$ Y.-K. Liu and M. H. Kryder, Appl. Phys. Lett. 77, 426-428 (2000).

${ }^{15}$ J. Das, S. S. Kalarickal, K.-S. Kim, and C. E. Patton, Phys. Rev. B 75, 094435 (2007).

${ }^{16}$ A. Gupta, R. Dubey, W. Leitenberger, and U. Pietsch, Appl. Phys. Lett. 92, 052504 (2008).

${ }^{17}$ R. Gupta, A. Gupta, W. Leitenberger, and R. Rüffer, Phys. Rev. B 85, 075401 (2012).

${ }^{18}$ N. G. Chechenin, A. van Veen, H. Schut, A. R. Chezan, D. O. Boerma, T Vystavel, and J. T. M. D. Hosson, J. Phys.: Condens. Matter 15, 7663 (2003).

${ }^{19}$ O. Shimizu, K. Nakanishi, and S. Yoshida, J. Appl. Phys. 70, 6244-6246 (1991).

${ }^{20}$ A. Chezan, C. Craus, N. Chechenin, T. Vystavel, L. Niesen, J. D. Hosson, and D. Boerma, J. Magn. Magn. Mater. 299, 219-2124 (2006).

${ }^{21}$ B. Viala, M. K. Minor, and J. A. Barnard, J. Appl. Phys. 80, 3941-3956 (1996).

${ }^{22}$ L. Varga, H. Jiang, T. J. Klemmer, W. D. Doyle, and E. A. Payzant, J. Appl. Phys. 83, 5955-5966 (1998).

${ }^{23}$ W. Jayasekara, S. Wang, and M. Kryder, J. Appl. Phys. 79, 5880-5882 (1996).

${ }^{24}$ P. Zou and J. A. Bain, J. Appl. Phys. 91, 6827-6829 (2002).

${ }^{25}$ F. Xu, S. Li, and C. K. Ong, J. Appl. Phys. 109, 07 D322 (2011).

${ }^{26}$ Z. W. Liu, D. C. Zeng, R. V. Ramanujan, and C. K. Ong, J. Appl. Phys. 107, 09A505 (2010).

${ }^{27}$ G. Rieger, G. Rupp, G. Gieres, R. Losehand, W. Hartung, W. Maass, and W. Ocker, J. Appl. Phys. 91, 8447-8449 (2002).

${ }^{28}$ F. Tessier, A. Navrotsky, R. Niewa, A. Leineweber, H. Jacobs, S. Kikkawa, M. Takahashi, F. Kanamaru, and F. J. DiSalvo, Solid State Sci. 2, 457 (2000).

${ }^{29}$ A. D. Mah and N. L. Gellert, J. Am. Chem. Soc. 78, 3261-3263 (1956).

${ }^{30}$ M. Kopcewicz, J. Jagielski, G. Gawlik, and A. Grabias, J. Appl. Phys. 78, 1312-1321 (1995).

${ }^{31}$ D. B. Evans, "Detemination of nitride solubility in the solvent liquid Iron," Ph.D. thesis, University of Michigan, 1963.

${ }^{32}$ E. Clementi, D. L. Raimondi, and W. P. Reinhardt, J. Chem. Phys. 47, 1300-1307 (1967).

${ }^{33}$ A. Tayal, M. Gupta, A. Gupta, M. Horisberger, and J. Stahn, Thin Solid Films 536, 39-49 (2013).

${ }^{34}$ M. Gupta, T. Gutberlet, J. Stahn, P. Keller, and D. Clemens, Pramana J. Phys. 63, 57 (2004).

${ }^{35}$ M. Gupta, A. Tayal, A. Gupta, V. Reddy, M. Horisberger, and J. Stahn, J. Alloys Compd. 509, 8283-8288 (2011)

${ }^{36}$ M. Gupta, A. Tayal, A. Gupta, R. Gupta, J. Stahn, M. Horisberger, and A. Wildes, J. Appl. Phys. 110, 123518 (2011)

${ }^{37}$ H. Oechsner, R. Getto, and M. Kopnarski, J. Appl. Phys. 105, 063523 (2009).
${ }^{38}$ N. Kardonina, A. Yurovskikh, and A. Kolpakov, Met. Sci. Heat Treat. 52, 457-467 (2011).

${ }^{39}$ D. M. Borsa and D. O. Boerma, Hyperfine Interact. 151-152, 31-48 (2003).

${ }^{40}$ M. Gupta, A. Gupta, P. Bhattacharya, P. Misra, and L. Kukreja, J. Alloys Compd. 326, 265-269 (2001).

${ }^{41}$ R. Gupta and M. Gupta, Phys. Rev. B 72, 024202 (2005).

${ }^{42}$ Y.-K. Liu, M. H. Kryder, D. H. Ryan, and Z. Altounian, J. Appl. Phys. 93, 6471-6473 (2003)

${ }^{43}$ L. Rissanen, M. Neubauer, K. P. Lieb, and P. Schaaf, J. Alloys Compd. 274, 74 (1998).

${ }^{44}$ P. Schaaf, Prog. Mater. Sci. 47, 1-161 (2002).

${ }^{45}$ E. Jiang, D. Sun, H. Liu, H. Bai, and X. Zhang, J. Magn. Magn. Mater. 140-144, 719-720 (1995).

${ }^{46}$ R. Dubey, A. Gupta, and J. C. Pivin, Phys. Rev. B 74, 214110 (2006).

${ }^{47}$ D.-L. Peng, K. Sumiyama, and K. Suzuki, J. Alloys Compd. 255, 50-54 (1997).

${ }^{48}$ E. B. Easton, T. Buhrmester, and J. Dahn, Thin Solid Films 493, 60-66 (2005).

${ }^{49}$ D. Moszyński, I. Moszyska, and W. Arabczyk, Mater. Lett. 78, 32-34 (2012).

${ }^{50}$ W. li Li, X. hang Zheng, and W. dong Fei, Vacuum 83, 949-952 (2009).

${ }^{51}$ T. Hinomura and S. Nasu, Physica B 237-238, 557-558 (1997).

${ }^{52}$ X. Wang, W. Zheng, H. Tian, S. Yu, W. Xu, S. Meng, X. He, J. Han, C. Sun, and B. Tay, Appl. Surf. Sci. 220, 30-39 (2003).

${ }^{53}$ B. D. Cullity, Elements of X-ray Diffraction (Addison-Wesley, MA, 1978).

${ }^{54}$ A. Guinier X-ray Diffraction (W. H. Freeman and Co., 1963).

${ }^{55}$ R. Gupta, A. Tayal, S. M. Amir, M. Gupta, A. Gupta, M. Horisberger, and J. Stahn, J. Appl. Phys. 111, 103520 (2012).

${ }^{56}$ Y. Yu, Y. Yang, Y. Shan, and X. Bi, Appl. Phys. Lett. 101, 232408 (2012).

${ }^{57}$ S. X. Wang and J. Hong, IEEE Trans. Magn. 35, 782-787 (1999).

${ }^{58}$ A. Svalov, I. R. Aseguinolaza, A. Garcia-Arribas, I. Orue, J. Barandiaran, J. Alonso, M. FernAndez-Gubieda, and G. Kurlyandskaya, IEEE Trans. Magn. 46, 333-336 (2010).

${ }^{59}$ R. Brand, NORMOS Mössbauer Fitting Program (Wissenschaftlich Elektronik GmbH, Starnberg, 1995).

${ }^{60}$ U. Gonser and H.-D. Pfannes, J. Phys. Collo. 35, C6-113 (1974).

${ }^{61}$ H. Schmidt, G. Borchardt, M. Rudolphi, H. Baumann, and M. Bruns, Appl. Phys. Lett. 85, 582-584 (2004).

${ }^{62}$ H. Schmidt, M. Gupta, and M. Bruns, Phys. Rev. Lett. 96, 055901 (2006).

${ }^{63}$ S. Chakravarty, M. Gupta, A. Gupta, S. Rajagopalan, A. Balamurugan, A. Tyagi, U. Deshpande, M. Horisberger, and T. Gutberlet, Acta Mater. 57, 1263-1271 (2009).

${ }^{64}$ M. Gupta, A. Gupta, J. Stahn, and T. Gutberlet, New J. Phys. 10, 053031 (2008).

${ }^{65}$ S. J. Blundell and J. A. C. Bland, Phys. Rev. B 46, 3391 (1992).

${ }^{66}$ M. P. Rosenblum, F. Spaepen, and D. Turnbull, Appl. Phys. Lett. 37, 184-186 (1980).

${ }^{67}$ J. Speakman, P. Rose, J. Hunt, N. Cowlam, R. E. Somekh, and A. Greer, J. Magn. Magn. Mater. 156, 411 (1996).

${ }^{68}$ M. Gupta, A. Gupta, J. Stahn, M. Horisberger, T. Gutberlet, and P. Allenspach, Phys. Rev. B 70, 184206 (2004).

${ }^{69}$ M.-A. Nicolet, Thin Solid Films 52, 415-443 (1978).

${ }^{70}$ H. Y. Wang, E. Y. Jiang, H. L. Bai, P. Wu, Y. Wang, and F. F. Gong, J. Phys.: Condens. Matter 9, 8443 (1997).

${ }^{71}$ Y. Ding, S. C. Byeon, and C. Alexander, Jr., IEEE Trans. Magn. 37, 1776-1778 (2001).

${ }^{72}$ Y. Ding and C. Alexander, Jr., IEEE Trans. Magn. 42, 5-11 (2006). 